\title{
Ciclosporina tópica como alternativa eficaz en el tratamiento de las queratitis intersticiales herpéticas
}

\section{Topical cyclosporine as an alternative treatment for herpetic interstitial keratitis}

\section{Sr. Director:}

La infección por el virus del herpes simple (VHS) continúa siendo la causa más frecuente de ceguera corneal en los países desarrollados, donde se producen entre 20,7 y 31,5 episodios por cada 100.000 personas, al año${ }^{1}$.

La enfermedad estromal por VHS puede presentarse en forma necrosante o no necrosante. Se cree que la querati- tis estromal no necrosante, que es la que nos atañe, constituye un proceso inmune que se presenta como queratitis intersticial o queratitis disciforme. La inflamación crónica - recurrente puede conducir a la pérdida visual por neovascularización, depósito de lípidos, fibrosis y adelgazamiento corneal.

En la queratitis intersticial, la reacción inflamatoria está mediada por antígeno-anticuerpo. Se ha visto que los linfoci- 
tos CD4+ juegan un papel muy importante en la misma. Por otro lado, la interleuquina-2 (IL-2) y el interferón gamma (IFN- $\gamma$ ) aparecen también aumentados en la fase aguda de la enfermedad. Todos estos mediadores activan una serie de células efectoras que destruyen el estroma ${ }^{2,3}$.

Tradicionalmente, se ha venido tratando con corticoides tópicos, pero la necesidad de tratamiento a muy largo plazo puede terminar produciendo complicaciones oculares graves.

La ciclosporina A es un inmunosupresor producido por un hongo (Tolypocladium inflatum) que interfiere selectivamente sobre las células inflamatorias sin producir efectos citotóxicos generalizados. Inhibiendo la ciclofilina, la ciclosporina A bloquea la transcripción y la producción de IL-2 por las células CD4+.

La ciclosporina A tópica se ha utilizado clínicamente en el tratamiento de diversas patologías de la superficie ocular de origen inflamatorio, como el síndrome de ojo seco, la queratoconjuntivitis vernal y las queratoconjuntivitis atópicas, con buenos resultados ${ }^{4}$. Por ello, iniciamos el tratamiento con este inmunosupresor tópico en nuestro centro, en una serie de cinco casos con queratitis intersticial de origen herpético ${ }^{5,6}$.

Presentamos una serie de cinco pacientes diagnosticados de queratitis intersticial de origen herpético, seguidos en nuestro servicio. Todos ellos en tratamiento con corticoides tópicos, corticodependientes, y con hipertensión ocular secundaria al tratamiento corticoesteroideo prolongado. Se decidió iniciar tratamiento con ciclosporina tópica al $1 \%$ cada ocho horas previa firma de un consentimiento informado específico, y fuimos disminuyendo de forma paulatina los corticoides tópicos, retirándolos por completo en un plazo de dos semanas. Tras la retirada del tratamiento esteroideo, todos los pacientes prescindieron del tratamiento hipotensor ocular. Todos ellos experimentaron mejoría subjetiva, y en los cinco se objetivó mediante lámpara de hendidura una disminución de la hiperemia conjuntival, disminución del edema corneal y aumento de la agudeza visual, llegando a 20/20 en cuatro de los cinco pacientes. Esta mejoría pudo observarse a partir de las dos semanas desde el inicio del tratamiento con ciclosporina tópica (fig. 1).

Tras dos meses de seguimiento, no se ha observado ningún efecto adverso local ni sistémico y la calidad de vida de los pacientes ha aumentado de forma considerable.

Por esta razón proponemos la ciclosporina tópica al 1\% como alternativa de tratamiento en aquellos pacientes con queratitis intersticial herpética de repetición, que desarrollan generalmente una corticodependencia.

No obstante, se precisan nuevos estudios con mayor número de pacientes que confirmen la eficacia e inocuidad de este tratamiento.

P. Palomares ${ }^{\text {a,* }}$, V. Del-Amo a , B. Moratal a,b ${ }^{\text {a. }}$. Montero ${ }^{\text {a }}$, M. Hernández ${ }^{a}$ y E. Cervera ${ }^{a, b}$

a Consorcio Hospital General Universitario de Valencia, Valencia, España ${ }^{b}$ Universidad de Valencia, Valencia, España

Correo electrónico: palomaresfort@gmail.com (Paula Palomares Fort)
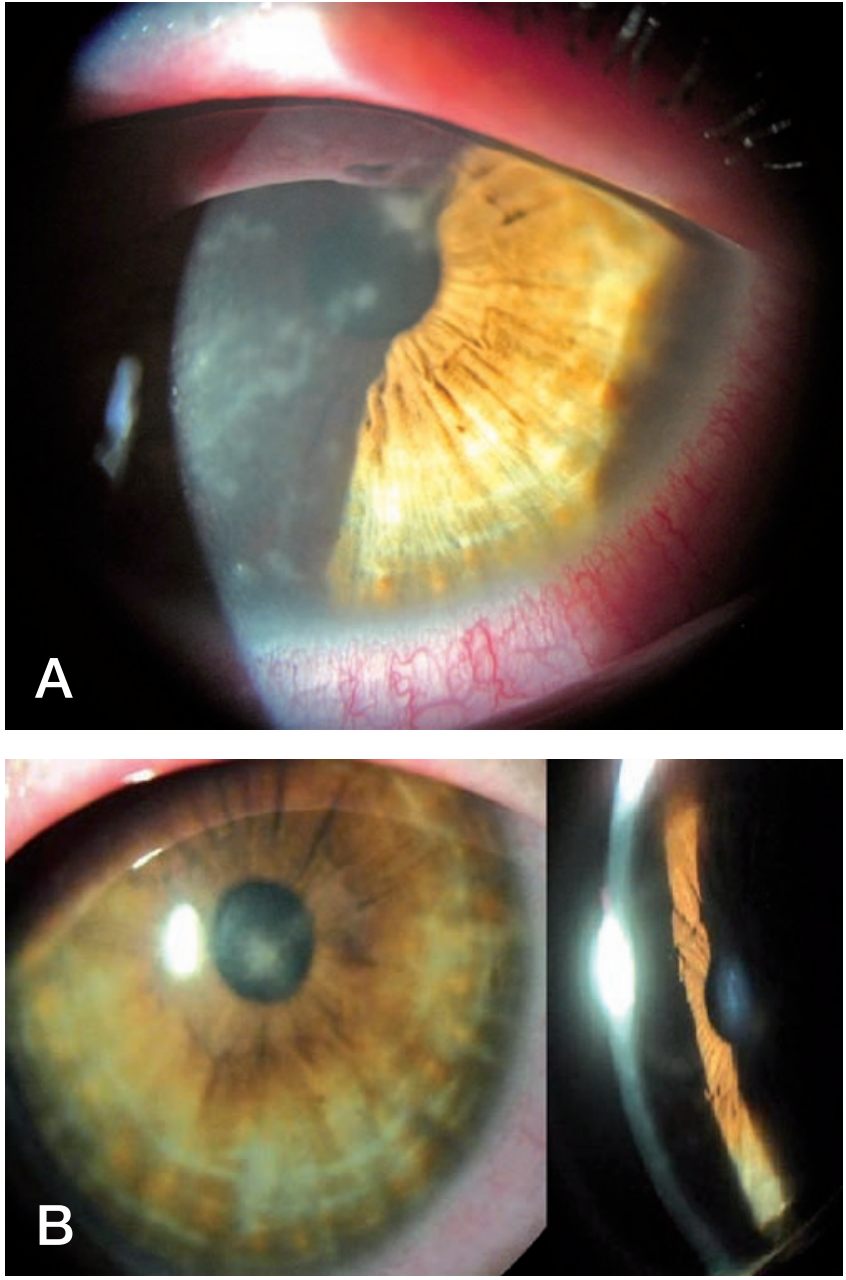

Figura 1 - Caso número 2. A. Biomicroscopía de polo anterior previa al inicio del tratamiento; B. Biomicroscopía un mes después del comienzo del mismo.

\section{B I B L I O G R A F Í A}

1. Knickelbein JE, Hendricks RL, Charukamnoetkanok P. Management of herpes simplex virus stromal keratitis: an evidence-based review. Surv Ophthalmol. 2009; 54(2):226-34. Review.

2. Doymaz MZ, Rouse BT. Herpetic stromal keratitis: an immunopathologic disease mediated by CD4+ T lymphocytes. Invest Ophthalmol Vis Sci. 1992;33(7):2165-73.

3. Yoon KC, Heo H, Kang IS, Lee MC, Kim KK, Park SH, et al. Effect of topical cyclosporin A on herpetic stromal keratitis in a mouse model. Cornea. 2008;27(4):454-60.

4. Donnenfeld E, Pflugfelder SC. Topical ophthalmic cyclosporine: pharmacology and clinical uses. Surv Ophthalmol. 2009;54(3):321-38. Review.

5. Heiligenhaus A, Steuhl KP. Treatment of HSV-1 stromal keratitis with topical cyclosporin A: a pilot study. Graefes Arch Clin Exp Ophthalmol. 1999;237(5):435-8.

6. Rao SN. Treatment of herpes simplex virus stromal keratitis unresponsive to topical prednisolone $1 \%$ with topical cyclosporine 0.05\%. Am J Ophthalmol. 2006;141(4):771-2. 